\title{
The Effects of Financial Literacy, Digital Financial Product Usage and Internet Usage on Financial Inclusion in China
}

\author{
Yan Shen ${ }^{1}$, Wenxiu $\mathrm{Hu}^{1}$ and C. James Hueng ${ }^{2}$ \\ ${ }^{1}$ Xi'an University of Technology, Accounting and Finance Department, 710054 Xi'an Shaanxi, China \\ ${ }^{2}$ Western Michigan University, Economics Department, 49008 Kalamazoo, MI, U.S.A
}

\begin{abstract}
This research study use partial least squares (PLS) to estimate a formative model which analyze effect of financial literacy, digital financial product usage, Internet usage on financial inclusion in mainland China. The study utilize a cross-sectional research design with a sample of 218 individuals from different areas of China participated. The results revealed that financial literacy and digital financial product usage have significant positive relationship with financial inclusion. Digital financial product usage is a mediator of the relationship between financial literacy and financial inclusion. Thus, digital financial product usage unites the Internet usage plays a multiple mediation role between financial literacy and financial inclusion. In short, the digital financial product usage had a partial mediating effect on the relationship between the Internet usage and financial inclusion. The findings indicate that improving the financial literacy of residents and popularizing the Internet usage can promote the use of digital financial products and achieve the goal of advancing financial inclusion.
\end{abstract}

\section{Introduction}

This research study construct a formative model to examine the effect of financial literacy, digital financial product usage and Internet usage on financial inclusion among individuals in mainland China. Chinese government regarded the digital finance as a useful tool to bridge the excluded groups and formal financial service.

There are great opportunities since the Chinese government shows a rapid adoption of Internet, mobile, and smart phones, which gives the normal Chinese greater access to digital financial services and products than ever before. China and African countries have different development models for digital currencies. African countries mainly promotes the use of mobile money through large mobile network operators. Its purpose is mainly to solve the problem of remittance. The Chinese government is committed to attracting low-income people to the Internet through the integration of banks, financial institutions, Internet financial platform, and social networks, and providing them with digital financial products and services via the Internet.

What is the effectiveness of the efforts of the Chinese government? Has the popularity of the Internet and the promotion of digital financial products improved financial inclusion? The answers to these questions enlighten us as to the current state of financial inclusion in China and has enabled us to identify policies to promote its usage.

The evidence on the effect of Internet usage and digital financial product usage on financial inclusion is lacking in this region, especially in China. Ren, Li, Zhao and Zhou (2018) [1] revealed that the more the understanding about digital finance, the lower the degree of Internet lending exclusion. When trying to reduce the probability of being excluded from Internet lending and the degree of being excluded, residents' education level should be increased. According to a study done by ADB (2016) ${ }^{[2]}$, the low level of financial literacy and low awareness of digital finance channels can decrease customers' support for digital financial channels to perform basic financial platforms. Fungáčová and Weill (2015) ${ }^{[3]}$ prove that education contribute to greater financial inclusion in China.

In 2017, a survey of "Internet and Digital Financial Product Usage" was conducted in different areas of China. This research study is the first one to construct a formative model among financial literacy, Internet usage, digital financial product usage and financial inclusion by using this survey data mentioned above. Partial least squares (PLS) method is utilized because it is suitable for the analysis of small samples and formative model. According to the experiences in China, this study focuses on the mediating role of digital financial product usage in the relationship among financial literacy, Internet usage, and financial inclusion. Conclusions are as followings: First, financial literacy and digital financial product usage have significant positive direct effect on financial inclusion. Secondly, digital financial products usage is a mediator between financial literacy and financial inclusion. The finding results demonstrate that the usage 
of the Internet has no impact on financial inclusion and the usage of digital financial products could promote the financial inclusion; however, the impact of the usage of digital financial products on financial inclusion will be affected by the level of financial literacy of customers.

The rest of the paper is outlined as follows: The next section contains the review of the necessary literature and hypotheses setting. Section 3 shows discussion of the methodology used in the study. Then section 4 focuses on results drawn from the study. Section 5 indicates the discussions and recommendation of the findings. Lastly, section 6 identifies the limitations to the study and areas for future studies.

\section{Literature review and research hypotheses}

\subsection{Financial literacy and financial inclusion}

Well-functioning financial systems serve vital purposes offering savings, credit, payment, and risk management products to people with a wide range of needs. Inclusive financial systems --- allowing broad access to financial services without price or non-price barriers to their use --these are likely to benefit poor people and other disadvantaged groups (Kunt \& Klapper, 2018) ${ }^{[4]}$. Therefore, financial inclusion is a multi-dimensional, pro-client concept, including better access, better products and services and better uses. Yet, Cohen and Nelson $(2011)^{[5]}$ point out that increased access and better choices do not automatically convert to effective use. Effective use is hindered by asymmetries of information and power between financial institutions and poor consumers. This imbalance increase as customers are less experienced and the products they can choose are more complex. Financial literacy is an important tool to address this imbalance and help consumers both accept and use the products to which they increasingly have access.

Despite the variations in different definitions, a general theme can be summarized as: "a combination of the understanding (knowledge), skills, attitude, and ability to make sound judgement and decision (behavior) on personal financial matters resulting in individual financial well-being" (Huston, 2010) [6]. Substantial empirical research has shown that the lack of basic knowledge of the financial concepts needed to make informed financial decisions is one of the key reasons associated with low demand for formal banking services (e.g., Giné \& Yang, 2009) [7]. Financial knowledge provides individuals with the knowledge and skills needed to assess whether financial products are suitable for their use to improve their financial status and financial inclusion (Braunstein \& Welch, 2002) [8]. Through compiled data supplied by Statistics Sweden into a panel of the entire population (about 4.8 million households) covering four years (1999-2002), Calvet, Campbell and Sodini (2009) [9] confirm that the households of higher financial literacy are less prone to making financial mistakes than other households. Klapper and Panos (2011) ${ }^{[10]}$ found that financial literacy is significantly and positively related to retirement planning involving private pension funds. Rooij, Lusardi and Alessie (2011) ${ }^{[11]}$ indicated that financial literacy affects financial decision-making. Those with low literacy are much less likely to invest in stocks.

Therefore, building a financially inclusive society requires improving financial literacy in terms of providing financial skills and knowledge as well as their application while making financial decisions. Atkinson and Messy (2011) ${ }^{[12]}$ note that financial literacy, in addition to improving individuals' ability to make informed financial decisions, enhances confidence, thereby improving a person's ability to easily access and use formal financial services.The study therefore, hypothesizes that:

$H 1$. Financial literacy is positively related to financial inclusion.

\subsection{Financial literacy and internet usage, digital financial product usage}

Some research was focused on the impact of financial literacy to Internet usage. Lama and Lamb (2017) ${ }^{[13]}$ found that financial knowledge can be regarded as a potential risk factor for Internet shopping. The results show that financial literacy is significantly and negatively correlated with Internet shopping by affecting the usage of the Internet.Rooij et al. (2011) ${ }^{[11]}$ found that those who display high levels of advanced literacy are much more likely to read newspapers and magazines, consult financial advisers, and seek information on the Internet. Servon and Kaestne (2008) ${ }^{[14]}$ mentioned that financial literacy, the digital divide, and other issues that separate vulnerable groups from the financial mainstream make it difficult for low- and moderate-income individuals to gain the potential benefits associated with computer banking.

Gerrard, Cunningham and Devlin (2006) [15] investigated why consumers are not using Internet banking. Lacking knowledge is an important factor that affect the adoption of Internet banking. Furthermore, Königsheim, Lukas and Nöth (2017) ${ }^{[16]}$ found that financial knowledge is significantly positively related with the probability to the usage of digital financial services. Therefore:

H2. There is a positive relationship between financial literacy and Internet usage.

H3. There is a positive relationship between financial literacy and digital financial product usage.

\subsection{Internet usage and digital financial product usage, financial inclusion}

Song and Hou (2017) ${ }^{[17]}$ discovered that there is a significantly positive correlation between the usage of Internet and the level of financial inclusion, based on the data of 25 developed countries and 40 developing countries. Gerrard et al. $\left(2006\right.$, p. 160) ${ }^{[15]}$ proved that "if a consumer did not own a PC and did not subscribe to an Internet service provider, he definitely cannot use Internet banking". Al-Rfou (2013) ${ }^{[18]}$ illustrated the factors that 
affect the adoption of Internet banking. He concluded that there is a significant relationship between the use of Internet, quality of Internet connection and the use of Internet banking. On the basis of prior empirical findings, the study hypothesizes that:

H4. Financial Internet usage is positively related to financial inclusion.

H5. Digital financial products usage is positively related to Internet usage.

\subsection{Digital financial product usage and financial inclusion}

Digital technology is the ideal medium to reach a large customer base across a wide territory. Voorhies (2014, p.169) ${ }^{[19]}$ showed that "if easy and affordable digital payment options were available to the most people in developing countries, we will solve the problem of financial inclusion. Data allow us to know which innovations work and which don't." Technological innovations are bringing both new customers (which may include millions of mobile phone users without bank accounts) and new service providers (various retail outlets, telecoms and others) into the market. Digital finance is critical to financial inclusion. Gabor and Brooks (2017) ${ }^{[20]}$ pointed that the digital revolution adds new layers to the material cultures of financial inclusion, offering the state new ways of expanding the inclusion of the legible, and global finance new forms of profiling poor households into generators of financial assets.

Kemal (2016) [21] explains that digital government-to-person payments include low-income families in society. The transition to electronic payments can combine social inclusion with the government's financial inclusion goals. Thus, we derive the hypothesis:

H6. Digital financial product usage is positively related to financial inclusion.

\section{Methodology}

\subsection{Model estimation}

Our model is a formative construct. Diamantopoulos and Winklhofer $(2001)^{[22]}$ point out several characteristics of formative models that make it sharply distinct from the reflective model. First, the indicators characterize a set of distinct causes which are not interchangeable as each indicator captures a specific aspect of the construct's domain (Jarvis, Mackenzie, \& Podsakoff, 2003) [23]. Second, components are not highly correlated (Petter, Straub \& Rai, 2007) ${ }^{[24]}$. Third, components cause (or contribute to) the underlying construct (Diamantopoulos, Riefler, \& Roth,2008) ${ }^{[25]}$. In the model, the causality is directed from the items to the construct and dropping one of the measures would affect the meaning of the construct, therefore the construct is formative (Petter et al., 2007) [24]. The research displays partial least squares (PLS) analysis was chosen for data analysis to test the effect among financial literacy, Internet usage, financial product usage and financial inclusion.

PLS has three advantages over LISREL for this study.
First, PLS does not require multivariate data as does the LISREL maximum likelihood estimation. Second, PLS is suitable for the analysis of small samples (Wold, 1985) [26]. Lastly, PLS has ability to dealing with formative model (Fornell \& Bookstein, 1982) ${ }^{[27]}$

As the number of our survey samples is not large enough (218) and the construct model is formative, the PLS is the best choice (Henseler, J, Christain \& Sinkovics, 2009) ${ }^{[28]}$. The estimation was performed using SmartPLS3.0 software to construct the measurement and the model.

\subsection{Sample}

To clarify our position we draw on some of previous works to produce a series of definitions in Table 1 to outline what we argue.

Data was collected from the respondents using a self-administered questionnaire. In phase one, the draft survey was presented to an expert panel of university teachers and some young people who have just worked. The university that this research was conducted at was Xi'an University of technology of China. This process lead to some alterations relating to item wording, duplication, layout and item sequencing as well as the addition of one new item. In phase two, an online and an offline investigation were undertaken with sample of 218 participants at the same time. Reliability of the data collection instrument was tested using Cronbach's $\alpha$ ( $\alpha$ 0.80 ) coefficient ensuring that all variables had $\alpha$ coefficients of 0.70 threshold. The analysis of the data indicated reliability was within acceptable ranges as recommended by Nunnally (1978) ${ }^{[29]}$.

Table 1. Definition of the study.

\begin{tabular}{|c|c|}
\hline Construct & Indicator \\
\hline \multirow{4}{*}{$\begin{array}{c}\text { Financial } \\
\text { Literacy }\end{array}$} & Education (Edu) \\
\cline { 2 - 2 } & Income (Inc) \\
\cline { 2 - 2 } & Commercial Loan (ComL) \\
\cline { 2 - 2 } & Credit Card (CC) \\
\cline { 2 - 2 } & Shares (Sha) \\
\cline { 2 - 2 } Internet & Commercial Financial Product (BCP) \\
\cline { 2 - 2 } Usage & Ontine Duration (OD) \\
\cline { 2 - 2 } & Internet Dependency (ID) \\
\hline \multirow{2}{*}{$\begin{array}{c}\text { Digital } \\
\text { financial } \\
\text { Product } \\
\text { Usage }\end{array}$} & Internet Financial Product (IFP) \\
\cline { 2 - 2 } & Internet Consumer Product (ICP) \\
\cline { 2 - 2 } & Internet Loan (IL) \\
\hline \multirow{2}{*}{$\begin{array}{c}\text { Financial } \\
\text { Inclusion }\end{array}$} & Crowd-funding (CF) \\
\cline { 2 - 2 } & Price Inclusion (PIn) \\
\cline { 2 - 2 } & Geographical Inclusion (GIn) \\
\hline
\end{tabular}

\subsection{Results}

The Construct Model combining predictor, mediator and outcome variables was constructed with direct paths from predictor to mediator and outcome variables as indicated 
in Figure 1.



Figure 1. Measurement model.

All of the paths estimated from the entire sample. Figure 1 and Table 2 present the outer weigh, path coefficient of the structural model. T-test could be used to test significance. The t-value can test whether this indicator applies to this latent variable. The indicators which have a level of $p<0.1$ could be recognized as significant (Fornell \& Bookstein, 1982) ${ }^{[27]}$.

Table 2. Diagnosistic test (bootstrap=1000).

\begin{tabular}{|c|c|c|c|c|c|}
\hline Variable & $\begin{array}{c}\text { Measurement } \\
\text { indicator }\end{array}$ & \begin{tabular}{|c|} 
Outer \\
Weight
\end{tabular} & $\mathrm{t}$ & $\mathrm{p}$ & VIF \\
\hline \multirow{7}{*}{$\begin{array}{l}\text { Financial } \\
\text { Literacy }\end{array}$} & $\mathrm{CC}$ & 0.457 & 3.727 & $<0.001$ & 1.523 \\
\hline & ComI & 0.212 & 2.083 & 0.037 & 1.346 \\
\hline & ComL & 0.172 & 1.431 & 0.153 & 1.43 \\
\hline & Inc & 0.127 & 1.144 & 0.253 & 1.736 \\
\hline & Edu & 0.351 & 2.69 & 0.007 & 1.625 \\
\hline & $\mathrm{BCP}$ & 0.064 & 0.508 & 0.612 & 1.248 \\
\hline & Sha & 0.03 & 0.301 & 0.764 & 1.319 \\
\hline \multirow{3}{*}{$\begin{array}{l}\text { Internet } \\
\text { Usage }\end{array}$} & OD & 0.141 & 1.05 & 0.294 & 1.584 \\
\hline & ID & 0.315 & 2.263 & 0.024 & 1.549 \\
\hline & TPP & 0.716 & 6.75 & $<0.001$ & 1.466 \\
\hline \multirow{4}{*}{\begin{tabular}{|l|} 
Digital \\
Financial \\
Product \\
Usage
\end{tabular}} & IFP & 0.554 & 4.685 & $<0.001$ & 1.28 \\
\hline & ICP & 0.278 & 1.739 & 0.082 & \begin{tabular}{|l|l|}
1.524 \\
\end{tabular} \\
\hline & IL & 0.406 & 2.415 & 0.016 & 1.09 \\
\hline & CF & 0.187 & 1.474 & 0.141 & 1.482 \\
\hline \multirow{3}{*}{$\begin{array}{l}\text { Financial } \\
\text { Inclusion }\end{array}$} & PIn & 0.269 & 1.483 & 0.138 & 1.428 \\
\hline & GIn & -0.024 & 0.182 & 0.856 & 1.276 \\
\hline & SIn & 0.85 & 6.272 & 0.000 & 1.404 \\
\hline
\end{tabular}

The results in Table 2 indicate that Credit Card, Commercial Insurance and Education can be used to measure financial literacy. The measurement weight of financial literacy for commercial loans, income, bank commercial financial product and shares is not significant. Internet Dependency and Third-party payment can be used to measure Internet usage. The measurement weight of Internet usage for online duration is not significant.
Internet Financial Product and Internet Loan can reflect latent variables well. The measurement weight of Internet consumer loan and crowd-funding on the use of digital financial products is not significant Self-inclusion is the most significant measurement indicator to Financial Inclusion. Price inclusion and geographic inclusion are not significant for measuring financial inclusion.

All VIF (Variance Inflation Factor) $<5$ indicate that the multicollinearity among latent variables is low (Sheather, 2009) [30].

Table 3 displays the intercorrelations between the constructs in the theoretical model. All correlations are significant (Fornell \& Bookstein, 1982) ${ }^{[27]}$.

Table 3. Correlation matrix.

\begin{tabular}{|c|c|c|c|c|}
\hline & $\begin{array}{c}\text { Digital } \\
\text { Financial } \\
\text { Product Usage }\end{array}$ & $\begin{array}{c}\text { Financial } \\
\text { Inclusion }\end{array}$ & $\begin{array}{c}\text { Financial } \\
\text { Literacy }\end{array}$ & $\begin{array}{c}\text { Internet } \\
\text { Usage }\end{array}$ \\
\hline $\begin{array}{c}\text { Digital } \\
\text { Financial } \\
\text { Product } \\
\text { Usage }\end{array}$ & 1 & 0.452 & 0.39 & 0.361 \\
\hline $\begin{array}{c}\text { Financial } \\
\text { Inclusion }\end{array}$ & 0.452 & 1 & 0.398 & 0.294 \\
\hline $\begin{array}{c}\text { Financial } \\
\text { Literacy }\end{array}$ & 0.39 & 0.398 & 1 & 0.563 \\
\hline $\begin{array}{c}\text { Internet } \\
\text { Usage }\end{array}$ & 0.361 & 0.294 & 0.563 & 1 \\
\hline
\end{tabular}

It can be seen in Fig. 1 and Table 4 that all of the related path coefficient is positive. Thus, six hypotheses were supported. A value of $\mathrm{R} 2=0.263$ is observed for the variable financial inclusion showing that financial literacy, digital financial product usage and Internet usage explained $26.3 \%$ of the total variance of financial inclusion. Additionally, it can be seen in Fig. 1 that the R2 value $=0.317$ for the Internet usage. The result indicated that financial literacy could explain $31.7 \%$ of the total variance of Internet use. An R2 value $=0.181$ is also observed for the variable digital financial product usage, demonstrating that the financial literacy and Internet usage influence $18.1 \%$ of the insertion into digital financial product usage. According to the recommendation from Cohen, J (1977) R2=13\% means medium effect, $\mathrm{R} 2=26 \%$ means large effect. This formative model could be accepted.

Table 4 shows total, direct and indirect effects in Construct Model. To test the hypotheses, the p-value and path coefficient criteria were chosen. For the p-value, a minimum confidence level of $95 \%(\alpha=$ or $<0.05)$ was defined, what is an error probability equal to or lower than $5 \%$, aiming t-values higher than 1.96 . For the path coefficients $(\beta)$, values higher than 0.20 were defined (Hair et al., 2016) ${ }^{[31]}$. According to Table 4, results provide evidence supporting $H 1, H 2, H 3, H 5, H 6$ with statistically significant $\beta$ ( $t$-value $>1.96, p<0.01)$. We can conclude that financial literacy and digital financial product usage is positively associated with financial inclusion separately; financial literacy is positively associated with Internet usage and digital financial product usage; Internet usage is positively associated with digital financial product usage. Only $H 4$ was not 
validated for the sake of $\mathrm{t}=0.375<1.96$, which demonstrating that "there is not a relationship between Internet usage and financial inclusion".

Table 4. Effects in Construct Model (Bootstrap=1000).

\begin{tabular}{|c|c|c|c|c|c|}
\hline Path & $\beta$ & $\begin{array}{c}\text { Boot } \\
\text { sample }\end{array}$ & $\begin{array}{c}\text { Standard } \\
\text { error }\end{array}$ & $\mathrm{t}$ & $p$ \\
\hline \begin{tabular}{|l} 
Financial \\
Inclusion
\end{tabular} & \multicolumn{5}{|c|}{$(\mathrm{R} 2=0.263)$} \\
\hline $\begin{array}{l}\text { Financial } \\
\text { Literacy } \rightarrow \text { FI }\end{array}$ & 0.246 & 0.256 & 0.084 & 2.935 & 0.003 \\
\hline $\begin{array}{l}\text { Internet } \\
\text { Usage } \rightarrow \text { FI }\end{array}$ & 0.031 & 0.029 & 0.083 & 0.375 & 0.708 \\
\hline $\begin{array}{lr}\text { Digital } & \text { Financial } \\
\text { Product } & \text { Usage } \\
\rightarrow \text { FI } & \\
\end{array}$ & 0.345 & 0.348 & 0.06 & 5.726 & $<0.001$ \\
\hline $\begin{array}{l}\text { Digital Financial } \\
\text { Product Use }\end{array}$ & \multicolumn{5}{|c|}{$(\mathrm{R} 2=0.181)$} \\
\hline $\begin{array}{l}\text { Financial } \\
\text { Literacy } \rightarrow \text { DFPU }\end{array}$ & 0.273 & 0.307 & 0.1 & 2.723 & 0.007 \\
\hline $\begin{array}{l}\text { Internet } \\
\text { Usage } \rightarrow \text { DFPU }\end{array}$ & 0.207 & 0.194 & 0.082 & 2.539 & 0.011 \\
\hline Internet Usage & \multicolumn{5}{|c|}{$(\mathrm{R} 2=0.317)$} \\
\hline $\begin{array}{l}\text { Financial } \\
\text { Literacy } \rightarrow \mathrm{IU}\end{array}$ & 0.563 & 0.57 & 0.055 & 10.189 & $<0.001$ \\
\hline
\end{tabular}

According to the results in Table 4, the internet usage and digital financial product usage may play and mediation effect between financial literacy and financial inclusion. In this study, the bootstrap procedure was used to test significance of the mediation using the direct and indirect mediation effects (Biesanz et al, 2010) ${ }^{[32]}$.

The analysis provided the average bootstrap estimate of indirect and direct effect and 95 per cent confidence intervals (CI). According to Howell D.C. $(2013)^{[33]}$ the results in Table 5 indicated that: Digital financial product usage significantly mediates the relationship between financial literacy and financial inclusion; secondly, digital financial product usage has significant mediation effect between Internet use and financial inclusion too; thirdly, digital financial product usage unites Internet usage plays a multiple mediation role between financial literacy and financial inclusion; lastly, there is insignificant mediation effect of Internet usage between financial literacy and financial inclusion.

\section{Conclusion}

Conclusively, the results of study showed that digital financial product usage and financial inclusion were significantly related. The usage of digital financial product creates the potential to make financial services available to a wider range of consumers and enterprises, promoting financial inclusion and the affordability of financial services. Digital financial product offers a new way to expanding the financial inclusion. In China, it is important to design risk - controlled products for customers who are excluded from the traditional finance. Through the construction of the Internet credit system, clients can have access to regulated and safe products on the Internet platform.

Table 5. Mediation regression weight.

\begin{tabular}{|c|c|c|c|c|}
\hline & \multirow{2}{*}{$\begin{array}{c}\text { Effect } \\
\text { size }\end{array}$} & $\begin{array}{c}\text { Standard } \\
\text { error }\end{array}$ & \multicolumn{2}{|c|}{$95 \%$ CI } \\
\cline { 3 - 5 } & & & & \\
\hline $\begin{array}{c}\text { Financial } \\
\text { Literacy } \rightarrow \text { Internet } \\
\text { Usage } \rightarrow \text { Financial } \\
\text { inclusion }\end{array}$ & 0.017 & 0.048 & -0.078 & 0.111 \\
\hline $\begin{array}{c}\text { Financial } \\
\text { Literacy } \rightarrow \text { Digital } \\
\text { Financial Product } \\
\text { Usage } \rightarrow \text { Financial } \\
\text { Inclusion }\end{array}$ & 0.106 & 0.037 & 0.037 & 0.187 \\
\hline $\begin{array}{c}\text { Financial } \\
\text { Literacy } \rightarrow \text { Internet } \\
\text { usage } \rightarrow \text { Digital } \\
\text { Financial Product } \\
\text { Usage } \rightarrow \text { Financial } \\
\text { Inclusion }\end{array}$ & 0.039 & 0.019 & 0.005 & 0.081 \\
\hline $\begin{array}{c}\text { Internet } \\
\text { Usage } \rightarrow \text { Digital } \\
\text { Financial Product } \\
\text { Usage } \rightarrow \text { Financial } \\
\text { Inclusion }\end{array}$ & 0.068 & 0.032 & 0.009 & 0.136 \\
\hline $\begin{array}{c}\text { Incion } \\
\text { nsang }\end{array}$ & & & & \\
\hline
\end{tabular}

This study indicated that financial literacy positively and significantly affect financial inclusion. Financial literacy provides financial knowledge and skills, which could help consumers make financial decisions. A certain level of financial literacy is required in order to use digital financial product and properly manage risks. In this regard, policy makers, managers and practitioners should be aware of the importance of financial literacy. They need to design financial literacy promotion policies. It is necessary to raise the financial literacy of residents as part of existing education systems to cultivate citizens' financial awareness. Financial literacy programs should be provided to Chinese citizens in different life stages.

Although there is insignificant relationship between Internet usage and financial inclusion, Internet usage unites digital financial product usage plays a multiple mediation role between financial literacy and financial inclusion and it plays as an indirect effect on financial inclusion through digital financial product usage. For the most part, this means that Internet usage could promote financial inclusion indirectly by acting on digital financial product usage. Actually, barriers to access may first need to be overcome before financial literacy and digital financial product can be effective. Internet is the best way to address the problem of access. Reducing costs is vital to promoting access. Policy makers can implement low to zero cost rating policies in rural areas to encourage residences to use Internet.

There is limited literature on digital financial product usage studies and the theoretical and empirical support on it. Since there is limited research literature on financial 
product usage due to the fact it is a specialized new field and costly, more extensive research may need to be conducted to get a better picture of its future outcomes.

This study was limited to using only a cross-sectional study design that provides a snapshot at a specific time period. Consumers' cognition and behaviors change over time including the environment, which may require investigation over a period of time to gain a better understanding.

Equally important, the research was conducted with urban residents in China. Clearly, this research should be replicated in other countries and rural areas in China as well because it has provided a valid foundation for further empirical research. Good governmental policies can provide the future full of opportunities and hope, especially for the poor populations in regard to the digital financial product usage.

\section{References}

1. B.Y. Ren, L.Y. Li, H.M. Zhao, Y.B. Zhou, Sin. Eco. Rev. 63, 65 (2018).

2. ADB, Asian Development Bank. (2016).

3. Z. Fungáčová, L. Weill, Chin. Eco. Rev. 34, 196 (2015).

4. A. D. Kunt, L. Klapper, The Global Findex Database (2018).

5. M. Cohen, C. Nelson, Global Microcredit Summit Commissioned Workshop Paper. (2011).

6. S. J. Huston, J. Cons. Aff. 44, 296 (2010).

7. X. Giné, D. Yang, J. Dev. Eco. 89, 1 (2009).

8. S. Braunstein, C. Welch, Fed. Res. Bul. 88, 445(2002).

9. L.Calvet, J.Campbell, P.Sodini, Am. Eco. Rev. 99, 393 (2009).

10. L. Klapper, G. A. Panos, J. Pens. Eco. Fin. 10, 599 (2011).

11. M. V. Rooij, A.Lusardi, R. Alessie, J. Fin. Eco. 101, 449 (2011).

12. A.Atkinson, F.Messy, OECD Working Papers (2013).
13. L. T. Lama, M. K. Lamb, Add. Beh. Rep. 6, 123 (2017)

14. L. J. Servon, R. Kaestner, J. Cons. Aff. 42, 271 (2008).

15. P. Gerrard, J. B.Cunningham, J. F. Devlin, J. Serv. Mark., 20, 160 (2006).

16. C. Königsheim, M. Lukas, M. Nöth, Sch. Bus. Rev. 18, 343(2017).

17. X. L.Song, J.C. Hou, Wor. Man. 19,172 (2017).

18. A. N. Al-Rfou, Asian. Eco. Fin. Rev. 3, 614 (2013).

19. R. Voiries, Am. Ban. 179 (2014).

20. D. Gabor, S. Brooks, New. Pol. Eco. 22, 423 (2016).

21. A.A. Kemal, Anglia Ruskin University (Doctoral dissertation), (2016).

22. A. Diamantopoulos, H. M. Winklhofer, J. Mark. Res. 38, 269 (2001).

23. C. Jarvis, S. Mackenzie, P. Podsakoff, J. Cons. Res. 30, 199 (2003).

24. S. Petter, D. Straub, A. Rai, MIS Qua. 31, 623 (2007).

25. A. Diamantopoulos, P. Riefler, K. P. Roth, J. Bus. Res. 61, 1203 (2008).

26. H. Wold, Encyclopedia of Statistical Sciences, (John Wiley \& Sons, New York, 1985).

27. C.Fornell, F. L. Bookstein, J. Mark. Res. 19, 440 (1982).

28. J. Henseler, M.R. Christain, RR. Sinkovics, Adv. Int. Mark. 20, 277 (2009).

29. J. C. Nunnally, Psychometric theory. (McGraw-Hill Book, New York, 1978).

30. S. J Sheather. A modern approach to regression with R. (Springer. New York,2009)

31. J F. Hair Jr., G. Tomas M., H. C. Ringle, M. Sarstedt, A primer on partial least squares structural equation modelling. (Sage Publications, California, 2016).

32. JC. Biesanz, C F. Falk, V.Savile, Mult.Beh.l Res. 45, $661(2010)$.

33. D.C. Howell, Statistical Methods for Psychology. (Wadsworth Publishing, Belmont, 2013). 